\title{
Wind tunnel modeling the system performance of alternative evaporative cooling pads in Taiwan region
}

\author{
Chung-Min Liao*, Kun-Hung Chiu \\ Department of Agricultural Engineering, National Taiwan University, Taipei 10617, Taiwan, ROC
}

Received 29 March 2000; received in revised form 14 September 2000; accepted 24 November 2000

\begin{abstract}
A compact wind tunnel was developed to simulate evaporative cooling pad-fan systems and to provide direct measurement of system performance. Two alternative materials including one made of coarse fabric PVC sponge mesh 2.5 mm diameter in pinhole and one made of fine fabric PVC sponge mesh in $7.5 \mathrm{~mm}$ diameter pinhole were tested as pads in wind tunnel experiment. We have experimentally examined the effects of air velocity, water flow rate, static pressure drop across pad, and pad thickness on evaporative cooling efficiency. Pad face velocities and associated static pressure drops that allow a pad-fan system works were measured. The dimensionless working equations of heat and mass transfer coefficients through various thickness of alternative pad media could be obtained through curve fitting technique based on the measurements. For coarse PVC sponge mesh, $h_{\mathrm{H}} / h_{\mathrm{M}}=1.33 \rho_{\mathrm{a}} C_{\mathrm{Pa}} L e^{2 / 3}\left(L e_{\mathrm{s}} / L e\right)^{1 / 4}$; whereas for fine fabric PVC sponge mesh, $h_{\mathrm{H}} / h_{\mathrm{M}}=2.76 \rho_{\mathrm{a}} C_{\mathrm{Pa}} L e^{2 / 3}\left(L e_{\mathrm{s}} / L e\right)^{1 / 4}$ were $h_{\mathrm{H}}$ is heat transfer coefficient, $h_{\mathrm{M}}$ is mass transfer coefficient, $\rho_{\mathrm{a}}$ is air density, $C_{\mathrm{Pa}}$ is specific heat of air, $L e$ is Lewis number, and $L e_{\mathrm{s}}$ is Lewis number at water temperature. Under a system setting of $151 \mathrm{~min}^{-1} \mathrm{~m}^{-2}$ water flow rate, pad thickness of $150 \mathrm{~mm}$, and air velocities ranged from 0.75 to $1.5 \mathrm{~m} \mathrm{~s}^{-1}$, the cooling efficiencies for coarse fabric PVC sponge varied from 81.75 to $84.48 \%$, whereas 76.68 to $91.64 \%$ for fine fabric PVC sponge. Results of this study will be used to determine operating protocols for future tests investigating criteria. (c) 2001 Elsevier Science Ltd. All rights reserved.
\end{abstract}

\section{Introduction}

Evaporative cooling process remains one of the least expensive techniques to bring dry-bulb temperature to a more comfortable range, and has been used to improve human comfort conditions since a long time in the thermal environmental control applications. Gates et al. [1], Bottcher et al. [2], Ryan et al. [3], Aljmal [4], Ali et al. [5], Arbel et al. [6], and among others reveal that evaporative cooling system has become a standard for many poultry houses and greenhouses and is used for swine and dairy cattle. The principle of evaporative cooling indicates that the evaporative cooling system can only remove room sensible heat, thus, the evaporative cooling system works best in hot and dry climate where the maximum evaporative cooling will result.

It is intuitively apparent that the evaporative cooling used in a moist climate, such as in Taiwan region, produces in-

\footnotetext{
${ }^{*}$ Corresponding author. Tel.: +886-2-2363-4512; fax: $+886-2-2362$ 6433.

E-mail address: cmliao@ccms.ntu.edu.tw (C.-M. Liao).
}

sufficient cooling and increases room relative and absolute humidity. Meteorological data, however, show that the mean relative humidity in Taiwan region always maintained at $50 \%$, whereas wet-bulb temperature is less than or equal to $25^{\circ} \mathrm{C}$ at noon and afternoon in the summer hours. More accurately, an evaporative cooling system could still enhance the cooling efficiency as long as the outdoor wet-bulb temperature is below or equal to $25^{\circ} \mathrm{C}$.

When the principle of evaporative cooling is used for a building, the rates of heat and mass transfer can be substantially increased by forcing the movement of air past an enlarged liquid water surface area for evaporation by utilizing blowers or fans. Practically, wet porous materials or pads can provide the large water surface in which the air moisture contact is achieved. The porous pad can be wetted by dripping water onto the upper edge of vertically mounted pads, by throwing or by spraying water onto the surface area face.

Manufacturers have tried pad materials of wood, metal, mineral, glass, plastic, and cement. More recently, new cellulose paper designs have been developed to make 


\begin{tabular}{|c|c|c|c|}
\hline \multicolumn{2}{|c|}{ Nomenclature } & $Q$ & ventilation rate $\left(\mathrm{m}^{3} \mathrm{~h}^{-1}\right)$ \\
\hline$A_{\mathrm{S}}$ & total welted pad surface $\left(\mathrm{m}^{2}\right)$ & Re & Reynolds number (dimensionless) \\
\hline$C_{1}, C_{2}$ & constants (dimensionless) & Sc & Schmidt number (dimensionless) \\
\hline$C_{\mathrm{Pa}}$ & $\begin{array}{l}\text { specific heat capacity of dry air }\left(\mathrm{kJ} \mathrm{kg}^{-1}\right. \\
\left.\mathrm{K}^{-1}\right)\end{array}$ & $S c_{\mathrm{s}}$ & $\begin{array}{l}\text { Schmidt number at water temperature (di- } \\
\text { mensionless) }\end{array}$ \\
\hline$D$ & $\begin{array}{l}\text { diffusion coefficient of water vapor air } \\
\left(\mathrm{m}^{2} \mathrm{~s}^{-1}\right)\end{array}$ & $\begin{array}{l}\text { Sh } \\
T_{1}, T_{2}\end{array}$ & $\begin{array}{l}\text { Sherwood number (dimensionless) } \\
\text { inlet and outlet dry-bulb temperature, respec- }\end{array}$ \\
\hline$h_{\mathrm{g} 1}, h_{\mathrm{g} 2}$ & transfer coefficient $\left(\mathrm{kJ} \mathrm{kg}^{-1}\right)$ & & tively $\left({ }^{\circ} \mathrm{C}\right)$ \\
\hline & heat transfer coefficient $\left(\mathrm{W} \mathrm{m}^{-1} \mathrm{~K}^{-1}\right)$ & $T_{\mathrm{wb}}$ & $\begin{array}{l}\text { wet-bulb temperature ( } \mathrm{C}) \\
\text { air velocity }\left(\mathrm{m} \mathrm{s}^{-1}\right)\end{array}$ \\
\hline & mass transfer coefficient $\left(\mathrm{m} \mathrm{h}^{-1}\right)$ & V & volume occupied by test pad media $\left(\mathrm{m}^{3}\right)$ \\
\hline$k$ & $\begin{array}{l}\text { thermal conductivity of dry air }\left(\mathrm{W} \mathrm{m}^{-1}\right. \\
\left.\mathrm{K}^{-1}\right)\end{array}$ & $W_{1}, W_{2}$ & $\begin{array}{l}\text { inlet and outlet humidity ratio, respectively } \\
\left(\mathrm{kg}_{\mathrm{w}} \mathrm{kg}_{\mathrm{a}}^{-1}\right)\end{array}$ \\
\hline$l$ & pad thickness $(\mathrm{mm})$ & & \\
\hline$l_{\mathrm{e}}$ & characteristic length $(\mathrm{mm})$ & \multicolumn{2}{|c|}{ Greek letters } \\
\hline Le & Lewis number (dimensionless) & $\alpha$ & thermal diffusivity $\left(\mathrm{m}^{2} \mathrm{~s}^{-1}\right)$ \\
\hline \multirow[t]{2}{*}{$L e_{\mathrm{s}}$} & Lewis number at water temperature (dimen- & $\Delta P$ & static pressure drop $(\mathrm{Pa})$ \\
\hline & sionless) & $\Delta T$ & $\log$ mean temperature difference for a con- \\
\hline$m_{2}$ & constants (dimensionless) & & stant water temperature $\left({ }^{~} \mathrm{C}\right)$ \\
\hline$m_{\mathrm{a}}$ & air mass flow rate $\left(\mathrm{kg} \mathrm{h}^{-1}\right)$ & $\Delta P_{V}$ & $\log$ mean mass density difference of water \\
\hline$m_{\mathrm{e}}$ & evaporated water rate $\left(\mathrm{kg} \mathrm{h}^{-1}\right)$ & & vapor (kg m ) \\
\hline & Nusselt number (dimensionless) & $\eta$ & cooling (saturation) efficiency $(\%)$ \\
\hline$P$ & atmospheric pressure $(\mathrm{Pa})$ & $v$ & kinematic viscosity $\left(\mathrm{m}^{2} \mathrm{~s}^{-1}\right)$ \\
\hline$P_{\mathrm{g}}$ & saturated water vapor $(\mathrm{Pa})$ & $\rho_{\mathrm{a}}$ & mass density of air $\left(\mathrm{kg} \mathrm{m}^{-3}\right)$ \\
\hline$P_{V}$ & partial pressure of water vapor $(\mathrm{Pa})$ & $\rho_{v 1}, \rho_{v 2}$ & mass densities of water vapor in the air stream \\
\hline $\operatorname{Pr}$ & Prandtl number (dimensionless) & & before and after evaporation cooling, respec- \\
\hline$P r_{\mathrm{s}}$ & $\begin{array}{l}\text { Prandtl number at water temperature (dimen- } \\
\text { sionless) }\end{array}$ & $\rho_{\mathrm{wb}}$ & $\begin{array}{l}\text { tively }\left(\mathrm{kg} \mathrm{m}^{-3}\right) \\
\text { mass density of water vapor at wet-bulb tem- }\end{array}$ \\
\hline$q$ & heat transfer rate $(\mathrm{W})$ & & perature $\left(\mathrm{kg} \mathrm{m}^{-3}\right)$ \\
\hline
\end{tabular}

evaporative cooling more efficient and more useful in different applications including industrial and residential sectors, greenhouses, cattle, poultry, and swine buildings, as well as storage warehouses [7-13]. These commercial pad materials are usually complicated to manufacture and they are costly and not readily available. Therefore, there is a need to evaluate the locally available materials for use as pads, particularly in rural agricultural areas.

Despite the widespread use of evaporative cooling pads currently in the market, relatively little information is available on the other alternative pad materials that also have enough pores to allow free flow of air to effect evaporation and capable of absorbing water and allow evaporation. Therefore, the present study aims to assess the technique feasibility of thermal environmental control systems that could be inexpensive, locally available, easily be constructed into the required shape, and visually attractive. One such solution is a system that includes evaporation of an exposed water film in which water is allowed to fall vertically over the elements such as polyviny 1 chloride (PVC) sponge, fibrous materials or other filaments. Giabaklou and Ballinger [14], Mathews et al. [15], Abdalla et al. [16], Liao et al. [17], and Dzivama et al. [18] suggested that alternative pad media such as gourd/stem sponge, jute fiber, charcoal, nylon, and coir fiber, can expose maximum surface area of water to the passing airflow with the help of forced or natural ventilation and the cooling efficiencies up to $85-90 \%$ could be reached for all the above materials. The arrangement of the fabric lines easily forms a water curtain through which the air flows horizontally. Based on these attributes, we chose locally available and inexpensive materials, PVC sponge with different fabric structures and pinhole sizes as test pad media.

Koca and coworkers [12] have developed a procedure for testing evaporative cooling pads. Their results show that pad performance is affected by pad angle, pad thickness, face air velocity, and static pressure drop across the pads and can be expressed in terms of evaporative cooling efficiency and static pressure drop.

A number of studies have been carried out to obtain better estimates of heat and mass transfer coefficients for evaporative cooling pads. Most of the studies, however, have focused on commercially available pad media and employed a great variety of test methods. Kimball et al. [7], Dowdy et al. [10] and Mannix [19] among others have experimentally determined, heat and mass transfer coefficients for evapora- 
tive cooling in aspen pads and a semi-empirical expression derived for sizing evaporative cooling equipment based on a given air velocity and pad efficiency. The same analysis employed by Dowdy et al. [10] applied also to rigid impregnated cellulose pads by Dowdy and Karabash [11].

The purposes of this paper are (1) to obtain the fundamental design information on the influence of air and water flow velocities on the heat and mass transfer coefficients for the evaporative process through various thickness of alternative pad media, and (2) to quantify effects of alternative pad designs related with saturation efficiency, face air velocity and static pressure drop across the pads.

The experimental pads were tested including a pad made of coarse fabric PVC sponge mesh with pinhole-sized in $2.5 \mathrm{~mm}$ diameter and one made of fine fabric PVC sponge mesh in a $7.5 \mathrm{~mm}$ diameter pinhole size. Because of the inherent difficulties in field measurements, a wind tunnel technique was developed to quantify system performance under more controlled conditions and to extend the range of test media analyzed. The procedure for determining required heat and mass transfer coefficients is based on the energy and water balances of an evaporative cooling pad system in order to estimate the systems parameters from the experimental data. Results are presented on dry- and wet-bulb temperatures, air flow rate, water flow rate, pad thickness, static pressure in transition, and a wide range of operating conditions.

\section{Material and methods}

\subsection{Wind tunnel system}

The measurements used to determine the heat and mass transfer coefficients and cooling efficiency were conducted in a laboratory wind tunnel system under a steady-state condition. An open, compact, low speed, temperature and humidity controlled wind tunnel is designed to achieve spatially uniform and steady free stream of air in a large portion of the test section. The design criteria followed were the conditions of air speed less than $10 \mathrm{~m} \mathrm{~s}^{-1}$, temperature less than $50^{\circ} \mathrm{C}$, and relative humidity range from 10 to $95 \%$ [20,21]. A schematic of the wind tunnel is depicted in Fig. 1. The apparatus may be divided into the following subsections for ease of discussion: rectifying contraction section; test/measurement section; and the air duct section.

The entrance to the rectifying contraction section is a fiber-glass constructed baffle $(600 \times 600 \mathrm{~mm})$. The honeycomb baffle (i.e., an anti-turbulence screen) design ensures a constant and evenly distributed air intake. The design minimizes turbulent airflow created by movement in front of intake. The back of the baffle has a contraction-cone-profile design that keeps the stream uniform, while decreasing the area to a $300 \times 300 \mathrm{~mm}$ cross-section. The rectifying contraction section is $700 \mathrm{~mm}$ in length and constructed of Plexiglass for easy viewing.

\begin{tabular}{ll}
\hline & Description \\
\hline 1.protection net & 7.transistor inverter \\
2.honeycomb baffle & 8.hot-wire anemometer \\
3.rectifying contraction section & 9. CR10 Micrologger \\
4.test section & $10 . P C$ \\
5.air duct section & $11 . T X-G S$ thermocouples \\
6. fan & 12. sump \\
\hline
\end{tabular}

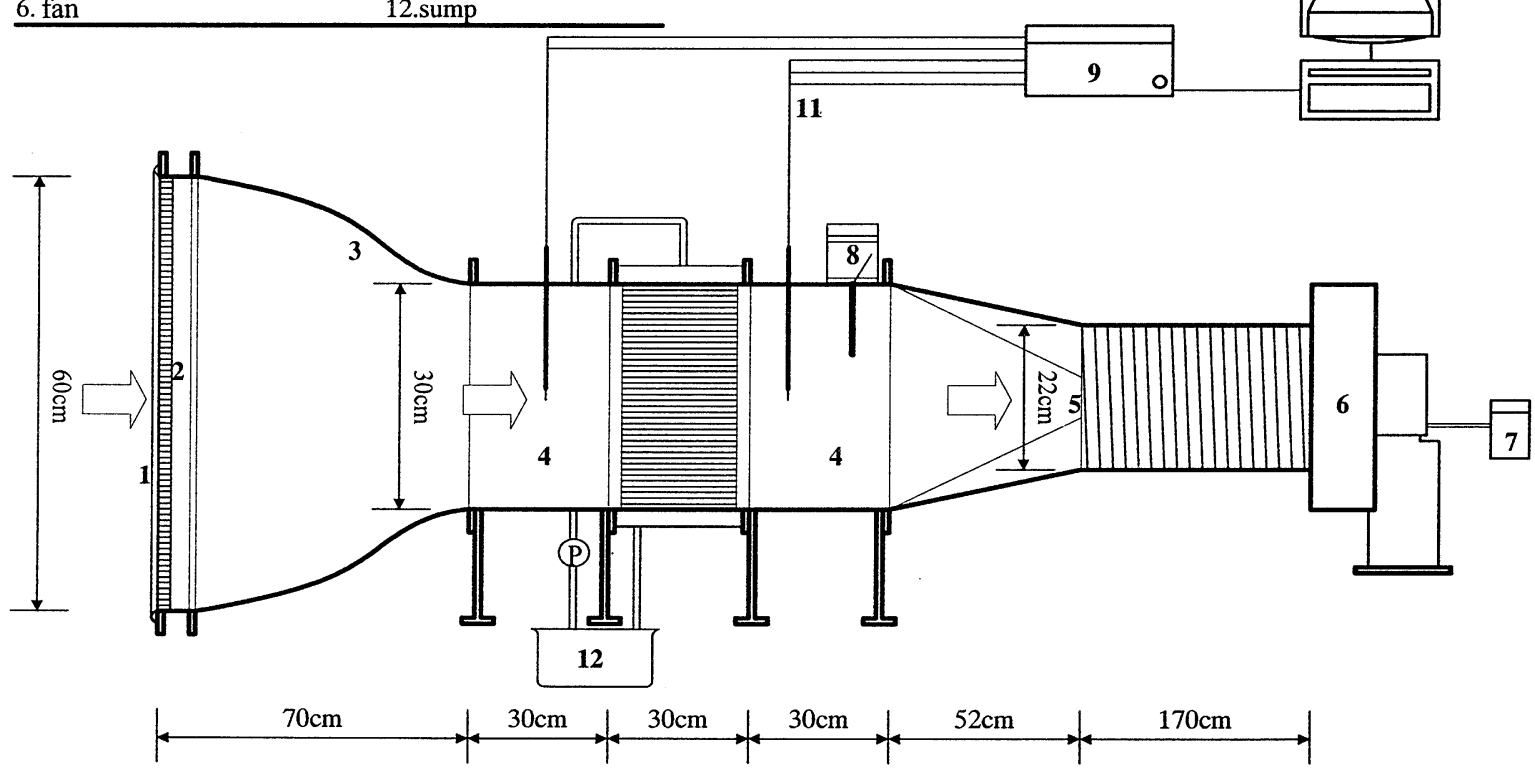

Fig. 1. A compact wind tunnel system used for the performance evaluation of alternative evaporative cooling pad media. 
The test section, $300 \times 300 \mathrm{~mm}^{2}$ is designed to accommodate up to a $150 \mathrm{~mm}$ thick cartridge of test pad media. In the front and back of the test section are the measurement sections measuring $300 \times 300 \mathrm{~mm}$. The measurement section contains the measuring points including dry- and wet-bulb temperatures, air velocity and static pressure drop across test pads. The top of the test section consists of a removable pan with $\mathrm{V}$-shaped perforations that feed water to test pad media. A valve mounted on the top surface of pan controls water flow. The bottom of the test section consists of a gutter through which excess water flows. Water flow rate was measured by collecting the water at this point. To ensure uniform water distribution from V-shaped perforations, the valve was adjusted with the top pan of the test section removed. When the required flows were obtained, the top pan was replaced and sealed with duct tape.

A circular metal duct with a profile design $(520 \mathrm{~mm}$ long and $300 \mathrm{~mm}$ diameter for inlet opening then decreasing to a $220 \mathrm{~mm}$ diameter) was attached to the rear measurement section. To the back of the circular metal duct, a $1700 \mathrm{~mm}$ long plastic-flexible round duct pipe of $300 \mathrm{~mm}$ diameter was attached. A centrifugal fan of $300 \mathrm{~mm}$ diameter driven by a multi-speed 1 HP 3-phase induction electric motor (Teco. Elec. and Mech. Co., Ltd., Taiwan) controlled by a transistor inverter (Kassuga Electric Works, Ltd., Japan) discharges the air through the wind tunnel. The powerful 12 A motor varying from 0 to $10,000 \mathrm{rpm}$ is adjusted to give a particular flow rate by precise motor control unit. The centrifugal fan contains a rotating impeller mounted inside a scroll type of housing imparts energy and air being removed. The motor and intake profiles utilize fiberglass construction, which minimizes airflow distortion.

\subsection{Procedure and instrumentation}

An environmentally controlled room is preferable for testing evaporative pads because temperature and humidity conditions can remain as constant as possible. To control room temperature, thermostatically controlled air conditioning was used so as to keep the room dry-bulb temperature at $25.5 \pm 1^{\circ} \mathrm{C}$.

Experimental pads were tested including a pad made of coarse fabric PVC (black) sponge mesh in a $2.5 \mathrm{~mm}$ diameter pinhole size (total pinhole area is about 0.22 of the cross-sectional area) and a pad made of fine fabric PVC (cream-colored) sponge mesh in a $7.5 \mathrm{~mm}$ diameter pinhole size (total pinhole area is about 0.6 of the cross-sectional area). Test pad modules are composed of several PVC sponge meshes joined together to make a structurally supporting module of thickness 50,100, and $150 \mathrm{~mm}$. A schematic showing the $50 \mathrm{~mm}$ test pad modules is illustrated in Fig. 2.

Air velocities were measured at the face of the measurement section in front of the test section with a directional hot-wire anemometer (Model 24-6111, Kanomax, Japan).
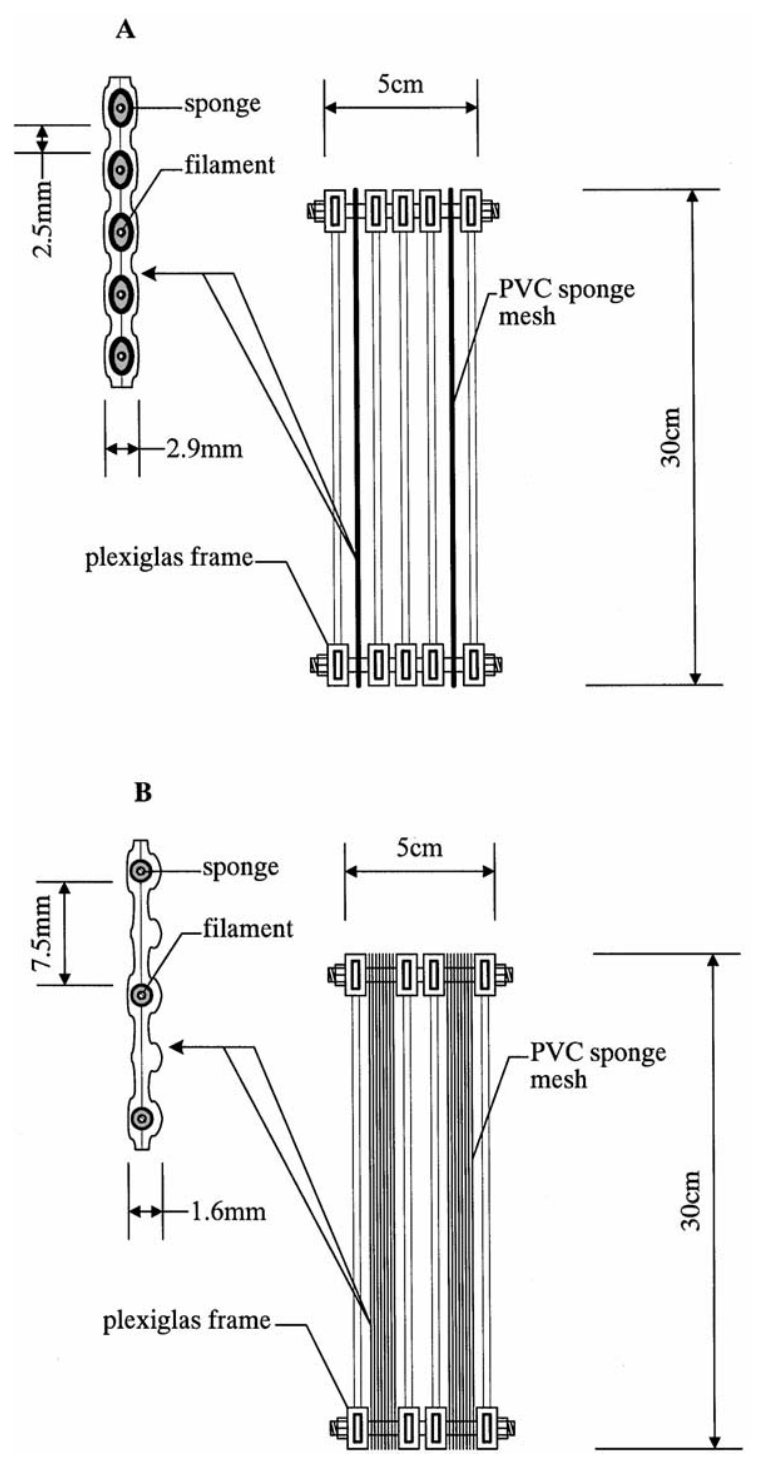

Fig. 2. Schematic illustration of $50 \mathrm{~mm}$ test pad modules for (A) coarse fabric PVC sponge mesh and (B) fine fabric PVC sponge mesh.

Anemometer calibration was checked before and after testing. The anemometer tip was placed in the vertical plane $150 \mathrm{~mm}$ in front of test pads. The air velocity was determined from the average value of hot-wire anemometer measurements at three locations.

All the temperatures were measured by means of the calibrated copper-constantan thermocouples (Model TX-GS). The temperature measurements used a bare thermocouple junction for dry-bulb temperature and a thermocouple junction wrapped with cotton gauze and wetted by siphon action from a gas dispersion tube for wet-bulb temperature. Copper-constantan thermocouples were deployed at three evenly spaced points on face of the test pad for dry-bulb temperature measurements in both front and rear measurement sections. A copper-constantan thermocouple placed near the entrance measured ambient dry-bulb temperature, and one cotton gauze wrapped thermocouple placed face the test pad, 
$150 \mathrm{~mm}$ in front measurement section for wet-bulb temperature of intake air. All thermocouple lines were placed in the monofilament tubing ( $2 \mathrm{~mm}$ i.d.) so that the thermocouple lines were not swayed along with air flow during testing. All temperatures were measured in duplicate which was mainly intended as a check on the wet-bulb temperatures.

Dry- and wet-bulb temperatures were manually recorded at all measuring positions during each test in order to validate thermocouple readings. The mean difference (manual-recorded) in dry-bulb temperature was $\pm 0.19^{\circ} \mathrm{C}$ with a standard deviation of $0.26^{\circ} \mathrm{C}$, while the mean difference in wet-bulb temperature was $\pm 0.06^{\circ} \mathrm{C}$ with 0.15 standard deviation.

Static pressure drop across the pads was measured with a directional hot-wire anemometer (Model 24-6111, Kanomax, Japan) by means of a resolution of $1.0 \mathrm{~mm} \mathrm{H}_{2} \mathrm{O}$. The pressure tip was centered vertically $150 \mathrm{~mm}$ upstream from the pad. A calibration curve for static pressure and air speed was used to validate anemometer readings; thus the man-made reading errors could be avoided. A polynomial relation was found between static pressure $\left(P_{\mathrm{s}}\right)$ and air velocity $(v)$ as $P_{\mathrm{s}}=44.24 v^{3}-3.13 v^{2}+47.65 v\left(r^{2}=0.99\right)$.

A stopwatch was used to measure the time required for the recirculation of water flow to fill a jar of known volume to determine the recirculation water flow rate in $1 \mathrm{~min}^{-1} \mathrm{~m}^{-2}$. Average recirculation water flows of 11 and $14.81 \mathrm{~min}^{-1} \mathrm{~m}^{-2}$ of cross-sectional area of test pad were initially used in test runs. Test results show that the pads were thoroughly saturated at a flow rate of $14.81 \mathrm{~min}^{-1} \mathrm{~m}^{-2}$, and a larger flow rate only caused more unevaporated water to become entrained in the air.

During the experiment, recirculation water was collected in a PVC tank, and recirculated with a centrifugal pump (Model 7520-20, Masterflex, Cole-Parmer Instrument Co., USA) through an adjustable gate valve and a flexible tubing of $15 \mathrm{~mm}$ diameter. Temperature of water circulating through the pad stabilized at the room wet-bulb temperature. A linear relation was found between the frequency of centrifugal pump $(\omega)$ and water pumping rate $\left(Q_{\mathrm{p}}, 1 \mathrm{~min}^{-1}\right)$ as $Q_{\mathrm{p}}=78.4 \omega-58.45\left(r^{2}=0.99\right)$.

Evaporative pads were wetted for $24 \mathrm{~h}$ before testing, and operated with airflow of approximately $0.5 \mathrm{~m} \mathrm{~s}^{-1}$ for $20 \mathrm{~min}$ before testing. Testing began with an air velocity of $0.5 \mathrm{~m} \mathrm{~s}^{-1}$ then increased to $0.75,1.0,1.25,1.5,1.75$, and $2.0 \mathrm{~m} \mathrm{~s}^{-1}$, respectively. A waiting period of at least $10 \mathrm{~min}$ between test increments ensured equilibrium between the pad and room air conditions that had been reached when air velocity was changed. The amount of drift or water entrainment off the pad face was noted at each test increment. All readouts were recorded on a computer-controlled data-acquisition system (Model CR10 Micrologger, Campbell Sci. Inc., USA) and monitored once every $1 \mathrm{~s}$. Eleven data sets based on a 2-min average readout were used in data analysis.

In order to find the actual area contained in the test pad, several samples of PVC sponge meshes were taken at ran-

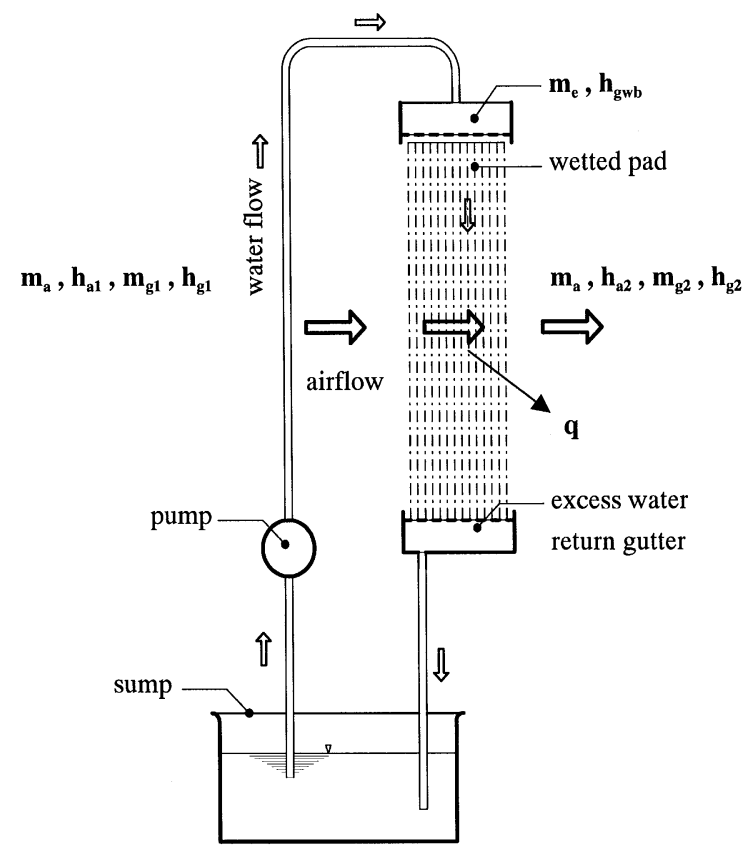

Fig. 3. Pathway of heat and mass transfer of moist air in a test pad with a water circulation system.

dom from test pads and immersed in water, until they became saturated. Pad thickness and pinhole size are assumed to be homogeneous and isotropic. The dimensions of individual wet pads were measured and the wetted surface area was calculated. The resulting values of total wetted surface are 1412.07 and $783.39 \mathrm{~cm}^{2}$, respectively, for coarse fabric $\mathrm{PVC}$ and fine fabric PVC sponge meshes.

\subsection{Mathematical modeling}

To find the most economic way of maintaining acceptable cooling efficiency in a pad-fan system, a quantitative model of the pad-fan system, with emphasis on the moist air balance, is required. To construct such a model, reliable heat and mass transfer coefficients must be available. An attempt was made to evaluate the required heat and mass transfer coefficients from the measurements in a wind tunnel, as a first step towards full-scale measurements.

The model selected, to form the basis of the thermodynamic process of evaporative cooling in the spaces, is a simple and a steady-state model. The elements of the model are inlet moist air, outlet moist air, wetted pad, and recirculation water. The approach adopted assumes that a single value of a variable such as temperature or humidity is representative of a whole element. In the evaporative cooling system the water is continuously recirculated and therefore the water temperature is close to ambient wet-bulb temperature. Therefore, the performance of the evaporative cooling system was carried out at different applied airflow rate and at constant water flow rate within the system. Fig. 3 gives a 
schematic illustration of the pathway of heat and mass transfer of moist air in a test pad with a water circulation system.

Under the assumptions of the model, a mathematical expression of heat and mass balances with the evaporative saturation efficiency on the evaporative cooling pad may be written for the system as (Fig. 3)

$m_{\mathrm{e}}=m_{\mathrm{a}}\left(W_{2}-W_{1}\right)$,

$q=\rho_{\mathrm{a}} C_{\mathrm{Pa}} Q\left(T_{1}-T_{2}\right)+\rho_{\mathrm{a}} Q\left(W_{1}\left(h_{\mathrm{g} 1}-h_{\mathrm{g} 2}\right)\right.$

$\left.-W_{2}\left(h_{\mathrm{g} 2}-h_{\mathrm{gwb}}\right)\right)$,

$\eta=\frac{T_{1}-T_{2}}{T_{1}-T_{\mathrm{wb}}}$

where $m_{\mathrm{e}}$ is the water evaporation rate $\left(\mathrm{kg} \mathrm{h}^{-1}\right), m_{\mathrm{a}}$ is the air mass flow rate $\left(\mathrm{kg} \mathrm{h}^{-1}\right): m_{\mathrm{a}}=\rho_{\mathrm{a}} Q$, in which $\rho_{\mathrm{a}}$ is the mass density of air $\left(\mathrm{kg} \mathrm{m}^{-3}\right)$ and $Q$ is the volumetric airflow rate $\left(\mathrm{m}^{3} \mathrm{~h}^{-1}\right), q$ is the heat transfer rate $(\mathrm{W}), T_{1}$ is the inlet dry-bulb temperature $\left({ }^{\circ} \mathrm{C}\right), T_{2}$ is the outlet dry-bulb temperature $\left({ }^{\circ} \mathrm{C}\right), C_{\mathrm{Pa}}$ is the specific heat of dry air $\left(\mathrm{kJ} \mathrm{kg}^{-1} \mathrm{~K}^{-1}\right), W_{1}$ is the inlet humidity ratio $\left(\mathrm{kg}_{\mathrm{w}} \mathrm{kg}_{\mathrm{a}}^{-1}\right), W_{2}$ is the outlet humidity ratio $\left(\mathrm{kg}_{\mathrm{w}} \mathrm{kg}_{\mathrm{a}}^{-1}\right), h_{\mathrm{g} 1}$ and $h_{\mathrm{g} 2}$ are the inlet and outlet enthalpy of saturated water vapor, respectively $\left(\mathrm{kJ} \mathrm{kg}^{-1}\right), h_{\mathrm{gwb}}$ is the enthalpy of saturated water vapor at thermodynamic wet-bulb temperature of the inlet air $\left(T_{\mathrm{wb}}\right)\left(\mathrm{kJ} \mathrm{kg}^{-1}\right)$, and $\eta$ is the evaporative saturation efficiency (\%).

Evaporative saturation efficiency $(\eta)$ is used to characterize evaporative systems, and works well when characterizing pad-fan systems, since the temperatures of the air entering and exiting the pads can be easily measured and used to calculate efficiency directly.

Using the product of heat or mass transfer coefficient with temperature difference $(\Delta T)$ or density difference of water vapor $\left(\Delta \rho_{v}\right)$ to proxy $q$ and $m_{\mathrm{e}}$ in Eqs. (1) and (2) we obtain

$q=h_{\mathrm{H}} A_{\mathrm{s}} \Delta T$

$m_{\mathrm{e}}=h_{\mathrm{M}} A_{\mathrm{s}} \Delta \rho_{v}$,

where $h_{\mathrm{H}}$ is the heat transfer coefficient $\left(\mathrm{W} \mathrm{m}{ }^{-2} \mathrm{~K}^{-1}\right), h_{\mathrm{M}}$ is the mass transfer coefficient $\left(\mathrm{m} \mathrm{h}^{-1}\right), A_{\mathrm{s}}$ is the total wetted surface area of pad media $\left(\mathrm{m}^{2}\right), \Delta T$ is taken to be the $\log$ mean temperature difference for a constant water temperature,

$\Delta T=\frac{\left(T_{2}-T_{1}\right)}{\ln \left(\left(T_{2}-T_{\mathrm{wb}}\right) /\left(T_{1}-T_{\mathrm{wb}}\right)\right)}$,

and $\Delta \rho_{v}$ is taken to be the log mean mass density difference of water vapor,

$\Delta \rho_{v}=\frac{\left(\rho_{v 2}-\rho_{v 1}\right)}{\ln \left(\left(\rho_{v 2}-\rho_{\mathrm{wb}}\right) /\left(\rho_{v 1}-\rho_{\mathrm{wb}}\right)\right)}$,

where $\rho_{v 1}$ and $\rho_{v 2}$ are the mass densities of the water vapor in the air stream before and after evaporative cooling $\left(\mathrm{kg} \mathrm{m}^{-3}\right)$, and $\rho_{\mathrm{wb}}$ is the mass density of water vapor at wet-bulb temperature.

If the values of the heat and mass transfer coefficients are not known, Eqs. (4) and (5) therefore can be used to evaluate them in the following manner:

$h_{\mathrm{H}}=\frac{q}{A_{\mathrm{s}}} \frac{\ln \left(\left(T_{2}-T_{\mathrm{wb}}\right) /\left(T_{1}-T_{\mathrm{wb}}\right)\right)}{\left(T_{2}-T_{1}\right)}=\frac{q}{A_{\mathrm{s}}} \frac{\ln (1-\eta)}{A_{\mathrm{s}}\left(T_{2}-T_{1}\right)}$,

$h_{\mathrm{M}}=\rho_{\mathrm{a}} Q \frac{\left(W_{2}-W_{1}\right)}{A_{\mathrm{s}}} \frac{\ln \left(\left(\rho_{v 2}-\rho_{\mathrm{wb}}\right) /\left(\rho_{v 1}-\rho_{\mathrm{wb}}\right)\right)}{\left(\rho_{v 2}-\rho_{v 1}\right)}$.

The filaments in the fabric of pad media carrying water in the system are analogous to that of flow across the banks (or bundles) of tubes. A correlation form describing the convective heat transfer associated with cross flow over a bank of tubes could be found in Incropera and DeWitt [22]. Applying the correlation form proposed in Incropera and DeWitt [22] to test pad media, the correlation relations may have the form

$N u=C_{1} \operatorname{Re}^{m_{1}} \operatorname{Pr}^{1 / 3}\left(\frac{P r}{P r_{\mathrm{s}}}\right)^{1 / 4}$,

where $N u$ is the Nusselt number, $R e$ is the Reynolds number, $P r$ is the Prandtl number, $P r_{\mathrm{s}}$ is the Prandtl number at water temperature, and $C_{1}$ and $m_{1}$ are the constants.

Assuming that the heat and mass transfer occurring in a given flow regime proceed at similar rates, a well-known modified Reynolds analogy between these processes produces the correlation form for mass transfer associated with cross-flow over tube bundles,

$S h=C_{2} \operatorname{Re}^{m_{2}} S c^{1 / 3}\left(\frac{S c}{S c_{\mathrm{s}}}\right)^{1 / 4}$,

where $S h$ is the Sherwood number, $S c$ is the Schmidt number, $S c_{\mathrm{S}}$ is the Schmidt number at water temperature, and $C_{2}$ and $m_{2}$ are the constants.

The definitions of above-noted dimensionless numbers are expressed as follows:

$R e=\frac{v l_{\mathrm{e}}}{v}, \quad N u=\frac{h_{\mathrm{H}} l_{\mathrm{e}}}{k}, \quad \operatorname{Pr}=\frac{v}{\alpha}, \quad S h=\frac{h_{\mathrm{M}} l_{\mathrm{e}}}{D}, \quad S c=\frac{v}{D}$,

where $v$ is the air velocity $\left(\mathrm{m} \mathrm{s}^{-1}\right), l_{\mathrm{e}}$ is the characteristic length $(\mathrm{m}): l_{\mathrm{e}}=V / A_{\mathrm{s}}$, in which $V$ is the volume occupied by the test pad media $\left(\mathrm{m}^{3}\right), v$ is the kinematic viscosity of dry air $\left(\mathrm{m}^{2} \mathrm{~s}^{-1}\right), k$ is the thermal conductivity of dry air ( $\mathrm{W} \mathrm{m} \mathrm{m}^{-1} \mathrm{~K}^{-1}$ ), $\alpha$ is the thermal diffusivity $\left(\mathrm{m}^{2} \mathrm{~s}^{-1}\right.$ ), and $D$ is the diffusion coefficient of water vapor into air $\left(\mathrm{m}^{2} \mathrm{~s}^{-1}\right)$.

In the wind tunnel experiment, all the necessary temperatures were measured so that using Eqs. (10) and (11) as regression equations the following evaluations are made possible: $\left(C_{2}, m_{2}\right)$ obtained from regression relations of $\mathrm{Nu} \mathrm{Pr}^{-1 / 3}\left(\operatorname{Pr} / \mathrm{Pr}_{\mathrm{s}}\right)^{-1 / 4}$ vs. $R e$, and $\left(C_{2}, m_{2}\right)$ obtained from regression relations of $S h S c^{-1 / 3}\left(S c / S c_{\mathrm{s}}\right)^{-1 / 4}$ vs. Re. 
A set of regression equations (as a function of temperature) for $\rho_{\mathrm{a}}, C_{\mathrm{Pa}}, v, k, \alpha, P r, D, h_{\mathrm{g}}, \rho_{v}, P_{\mathrm{g}}$, and $P_{v}$ is derived based on the thermophysical properties of air and water vapor at atmospheric pressure [23-25] to calculate the various dimensionless numbers as well as the heat and mass transfer coefficients.

\section{Results and discussion}

\subsection{General description of results}

Figs. 4A and $\mathrm{B}$ give the effects of face velocity on pressure drop across the pads and on cooling efficiency of the pads, respectively. Both the 100 and $150 \mathrm{~mm}$ pads exhibited high-pressure drops (101.4-202.5 Pa) when face velocities ranged from 1.5 to $2.0 \mathrm{~m} \mathrm{~s}^{-1}$ (Fig. 4A). The $15 \mathrm{~cm}$ pad operated at a pressure approximately $14.2 \%$ more than a $100 \mathrm{~mm}$ pad. In this test, velocities greater than $1.75 \mathrm{~m} \mathrm{~s}^{-1}$ tended to pull free water into the air stream. Because of pressure increases always at high velocity, this test suggests that face velocity of $0.75-1.5 \mathrm{~m} \mathrm{~s}^{-1}$ is recommended for coarse fabric PVC sponge mesh.

Fig. 4B shows that cooling efficiencies above $86 \%$ for face velocities up to $0.75 \mathrm{~m} \mathrm{~s}^{-1}$ in the $150 \mathrm{~mm}$ pad, above $81 \%$ up to $0.5 \mathrm{~m} \mathrm{~s}^{-1}$ in the $100 \mathrm{~mm}$ pad, and above $61-70 \%$ up to $2 \mathrm{~m} \mathrm{~s}^{-1}$ in the $50 \mathrm{~mm}$ pad, respectively.
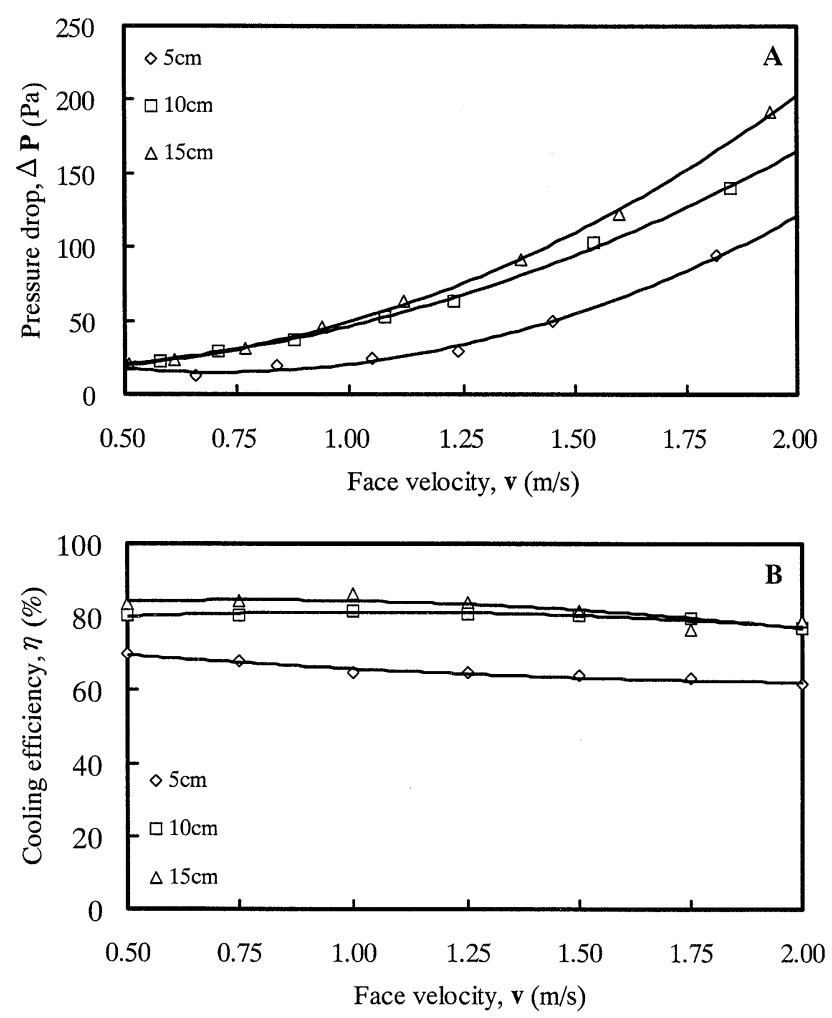

Fig. 4. Test results for coarse fabric PVC sponge mesh of the effects of face velocity on (A) pressure drop in transition and (B) cooling efficiency.
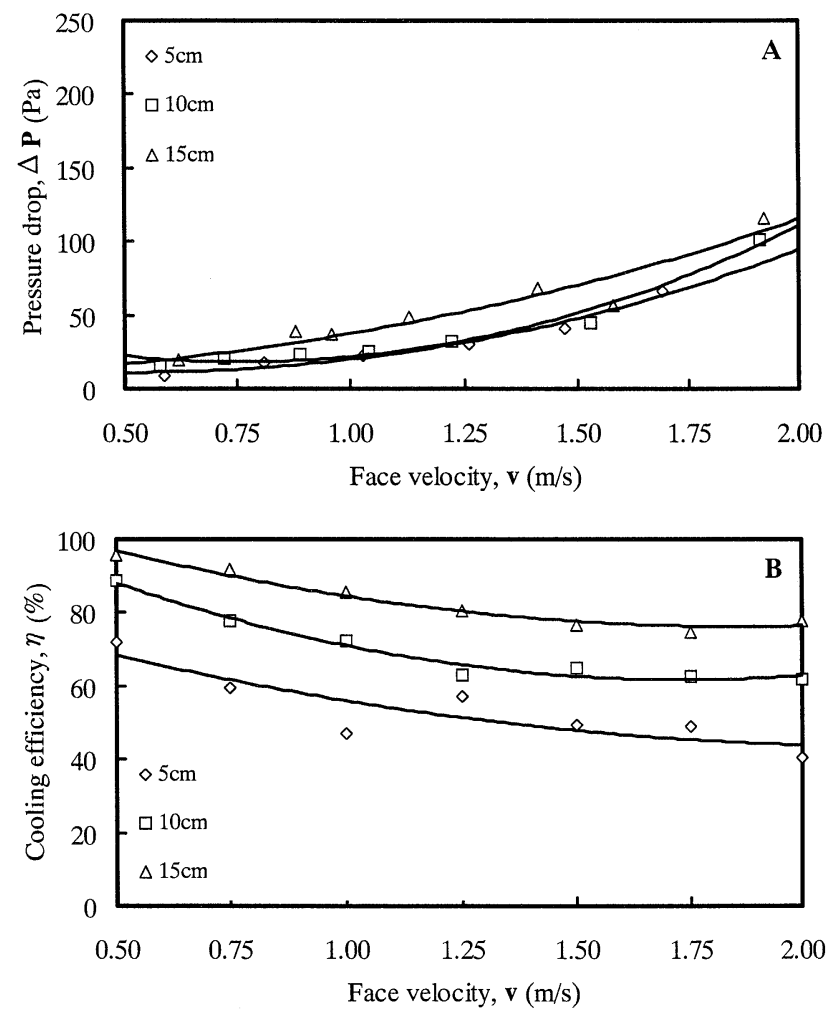

Fig. 5. Test results for fine fabric PVC sponge mesh of the effects of face velocity on (A) pressure drop in transition and (B) cooling efficiency.

The effects of face velocity on pressure drop, across pads, and on cooling efficiency for fine fabric PVC sponge mesh are illustrated in Figs. 5A and B, respectively. Fig. 5A shows that a pad of $50 \mathrm{~mm}$ thickness ranged in pressure drop from 9.8 to $15 \mathrm{~Pa}$ at face velocities of $0.5-2.0 \mathrm{~m} \mathrm{~s}^{-1}$. A $100 \mathrm{~mm}$ pad exhibited a pressure drop much closer to a $50 \mathrm{~mm}$ pad than to a $150 \mathrm{~mm}$ pad. A $150 \mathrm{~mm}$ pad operated at a pressure approximately $19.4 \%$ more than a $100 \mathrm{~mm}$ pad.

Fig. 5B indicates that pad of $50 \mathrm{~mm}$ thickness ranged in cooling efficiencies from 72.03 to $40.56 \%$ at face velocities of $0.5-2.0 \mathrm{~m} \mathrm{~s}^{-1}$. A $100 \mathrm{~mm}$ pad operated in cooling efficiency closer to that of a $50 \mathrm{~mm}$ pad. A $100 \mathrm{~mm}$ thickness pad ranged in cooling efficiencies from 88.65 to $61.99 \%$ at velocities of $0.5-2.0 \mathrm{~m} \mathrm{~s}^{-1}$. Fig. $5 \mathrm{~B}$ also shows that 150 $\mathrm{mm}$ pad operated within a cooling efficiency range of 74.71$95.50 \%$ at velocities decreasing from 2.0 to $0.5 \mathrm{~m} \mathrm{~s}^{-1}$. In addition, thicker perforated pads performed at higher cooling efficiency, $16 \%$ higher than of a $100 \mathrm{~mm}$ pad which operates $24 \%$ higher than that of a $50 \mathrm{~mm}$ pad.

Experimental results apply only to the pads tested and are not general design values. Generally, greater pressure drops are obtained with thicker pads. The results compare to that of Murr and Zaleski [9] and Koca et al. [12] closely.

One factor that can affect the pressure measurement is the location of the static pressure tap. Because the procedure presented for this study uses pressures obtained from the $300 \mathrm{~mm}$ pad, no entrance loss effects are included and data 

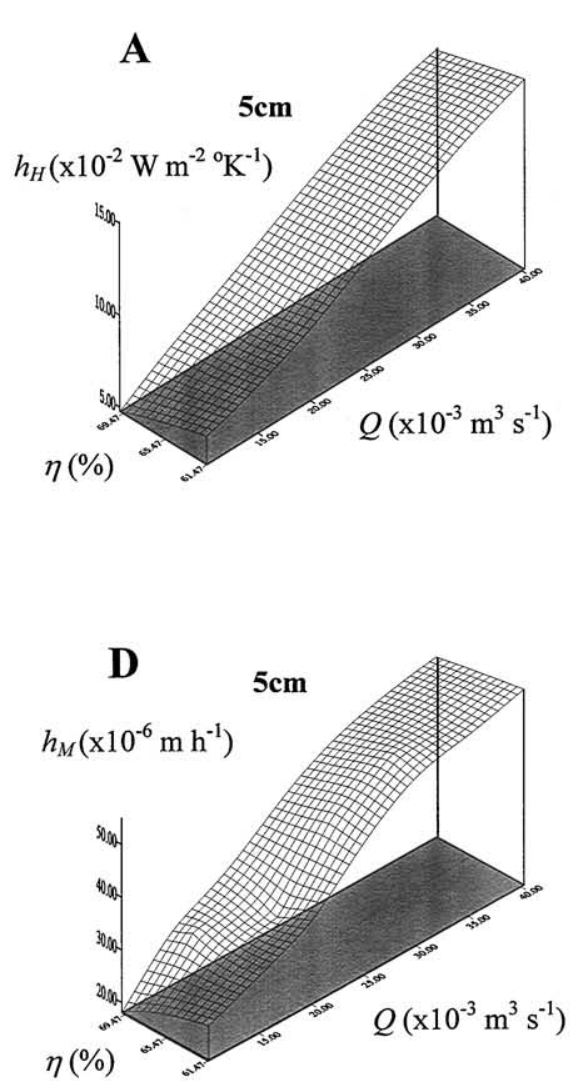
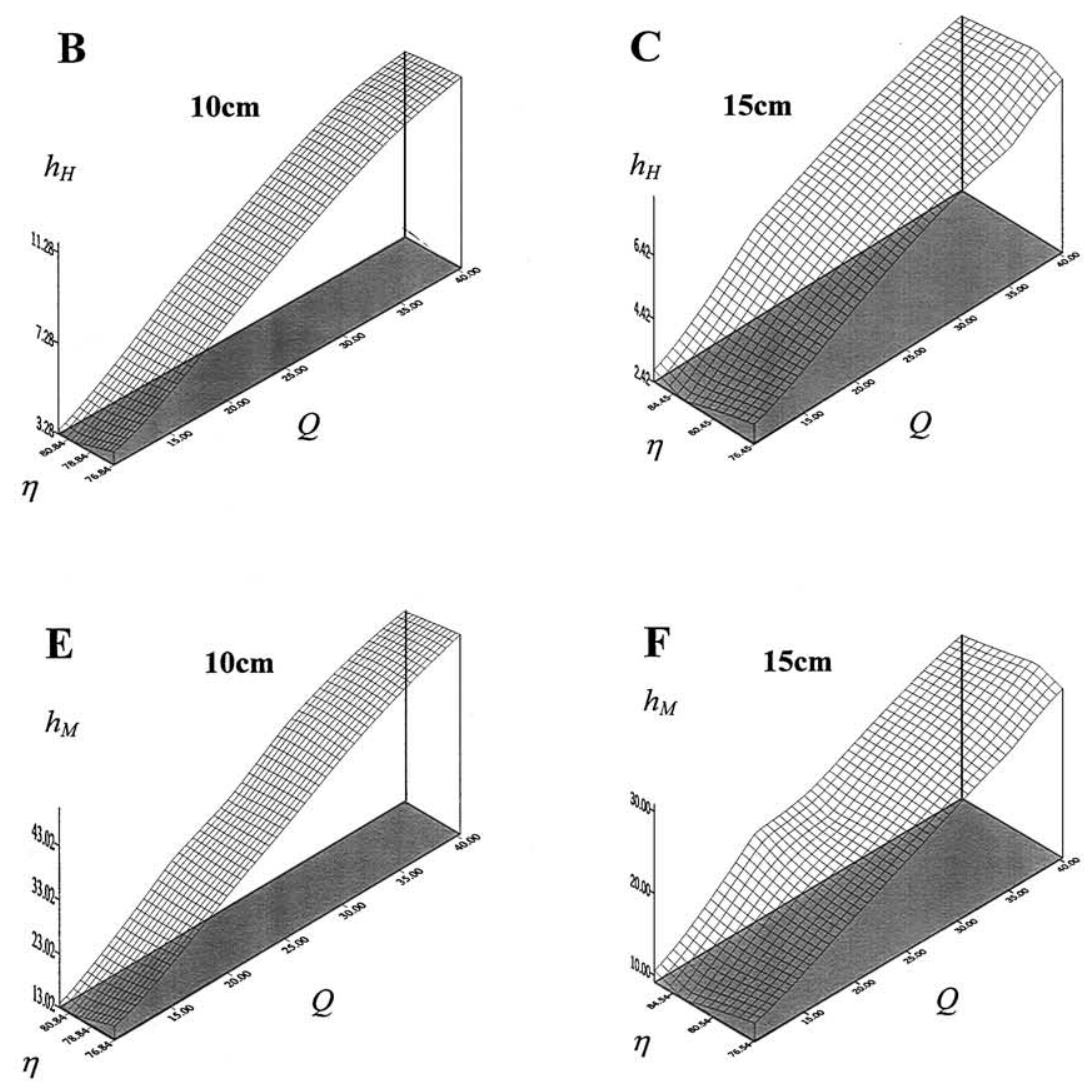

Fig. 6. Response surfaces of calculated transfer coefficients of heat (A-C) and mass (D-F) varied with cooling efficiency and volumetric air flow rate for 50,100 and $150 \mathrm{~mm}$ thick coarse fabric PVC sponge mesh.

obtained are representative of pads operating in the fields. Water flow rate also affects pressure drop. It was determined that an increase in water flow rate increased the resistance of the pad, therefore, the static pressure increased. Test results thus reveal that pinhole size and fabric structure effect pressure drop in transition.

Generally, higher efficiencies are obtained with thicker pads, and slower air velocities. The results reflect greater evaporative rates as air takes more time to travel through the pad. Therefore, the amount of time allowed for the pad to reach equilibrium with room air conditions between test increments needs to be indicated. If tests were performed without allowing sufficient time for the pad to adjust to higher air flow, artificially high efficiencies could be observed, since pads are wetter at lower air velocities due to less evaporation taking place. By the same situation, decreasing the airflow without allowing sufficient time for the pad to reach equilibrium with room air conditions could result in lower efficiencies than what is realized in field installations.

\subsection{Transfer coefficients}

Calculated heat and mass transfer coefficients, for 50, 100, and $150 \mathrm{~mm}$ thick coarse fabric PVC and fine fabric PVC sponge meshes which varied with cooling efficiency and volumetric air flow rate are arranged as the response surfaces and are illustrated in Figs. 6 and 7, respectively. Fig. 6 indicates that $h_{\mathrm{H}}$ values were estimated in ranges $0.048-0.15$, $0.033-0.12$, and $0.024-0.083 \mathrm{~W} \mathrm{~m}^{-2} \mathrm{~K}^{-1}$ as well as that of $h_{\mathrm{M}}$ in ranges $1.8 \times 10^{-5}-5.5 \times 10^{-5}, 1.3 \times 10^{-5}-5.0 \times 10^{-5}$, and $9.0 \times 10^{-6}-3.1 \times 10^{-5} \mathrm{~m} \mathrm{~h}^{-1}$, respectively, for 50,100 , and $150 \mathrm{~mm}$ thick coarse fabric PVC sponge mesh under operating airflow rates of $0.01-0.04 \mathrm{~m}^{3} \mathrm{~s}^{-1}$. Fig. 7 indicates values of $0.03-0.05,0.026-0.046$, and $0.025-0.049 \mathrm{~W} \mathrm{~m}^{-2} \mathrm{~K}^{-1}$ for $h_{\mathrm{H}}$ as well as values of $1.2 \times 10^{-5}-2.1 \times 10^{-5}, 1.0 \times 10^{-5}-1.8 \times 10^{-5}$, and $9.0 \times 10^{-6}-1.9 \times 10^{-5} \mathrm{~m} \mathrm{~h}^{-1}$ for $h_{\mathrm{M}}$, respectively, for 50 , 100 , and $150 \mathrm{~mm}$ thick fine fabric PVC sponge mesh under operating airflow rates of $0.027-0.11 \mathrm{~m}^{3} \mathrm{~s}^{-1}$.

Correlation studies followed by Eqs. (10) and (11) revealed that an additional dimensionless parameter related to the pad thickness is needed (Figs. 8B, D, 9B, and D). As a result, $l_{\mathrm{e}} / l$ is added to Eqs. (10) and (11) to obtain calibrated correlation equations. Therefore, length dimensions used in $R e, N u$, and $S h$ were the characteristic lengths $l_{\mathrm{e}}$ $\left(l_{\mathrm{e}}=V / A_{\mathrm{s}}\right)$; the resulting values for coarse fabric PVC and fine fabric PVC sponge meshes are 1.848 and $1.838 \mathrm{~mm}$, respectively.

Figs. 8A and $\mathrm{C}$ show the calibrated correlation of nondimensionalized heat and mass transfer coefficients for coarse fabric PVC sponge mesh. With the addition of the dimen- 

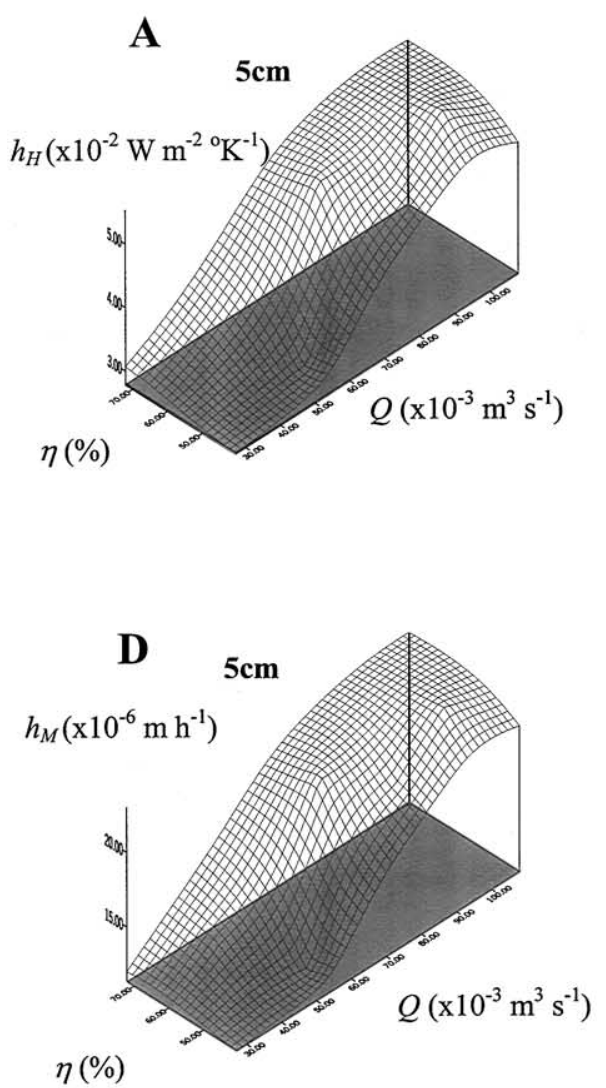
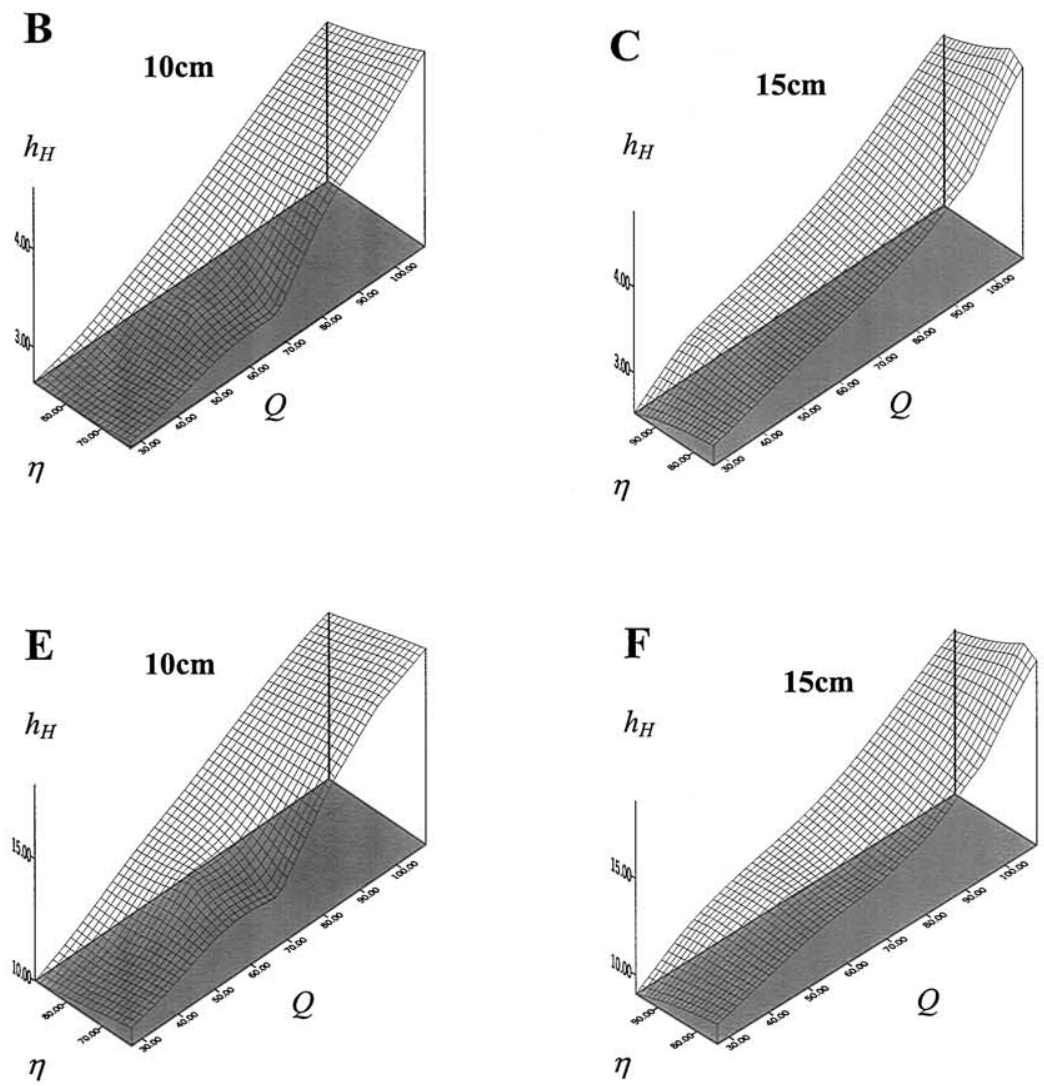

Fig. 7. Response surfaces of calculated transfer coefficients of heat (A-C) and mass (D-F) varied with cooling efficiency and volumetric air flow rate for 50, 100 and $150 \mathrm{~mm}$ thick fine fabric PVC sponge mesh.

sionless pad thickness the following calibrated correlations were found by least-squares fitting (Figs. 8A and C):

$N u=4 \times 10^{-4}\left(\frac{l_{\mathrm{e}}}{l}\right)^{0.45} \operatorname{Re}^{0.89} \operatorname{Pr}^{1 / 3}\left(\frac{P r}{\operatorname{Pr}_{\mathrm{s}}}\right)^{1 / 4}$,

$r^{2}=0.981$,

$S h=3 \times 10^{-4}\left(\frac{l_{\mathrm{e}}}{l}\right)^{0.45} \operatorname{Re}^{0.89} \operatorname{Pr}^{1 / 3}\left(\frac{S c}{S c_{\mathrm{s}}}\right)^{1 / 4}$,

$r^{2}=0.957$

The properties in this correlation are those of dry air at the average dry-bulb temperature. For heat transfer, the average deviation of the data point from the correlation equation is $2.56 \%$. For the mass transfer, the average deviation of the data is $2.65 \%$.

The calibrated correlation of nondimensionalized heat and mass transfer coefficients for fine fabric PVC sponge mesh are shown in Figs. 9A and C. The calibrated correlation equations were found as follows (Figs. 9A and C):

$N u=4.7 \times 10^{-3}\left(\frac{l_{\mathrm{e}}}{l}\right)^{0.19} \operatorname{Re}^{0.43} \operatorname{Pr}^{1 / 3}\left(\frac{P r}{\operatorname{Pr}_{\mathrm{s}}}\right)^{1 / 4}$, $r^{2}=0.762$

$S h=1.7 \times 10^{-3}\left(\frac{l_{\mathrm{e}}}{l}\right)^{0.19} \operatorname{Re}^{0.43} \operatorname{Pr}^{1 / 3}\left(\frac{S c}{S c_{\mathrm{s}}}\right)^{1 / 4}$,

$r^{2}=0.771$.

For heat transfer, the average deviation of the data points from the correlation equation is $3.33 \%$. For mass transfer, the average deviation of the data is $3.13 \%$. Generally, as the pad thickness increases, the heat and mass transfer coefficients decrease as the flow continues to develop. With sufficient increase in pad thickness, it is expected that both, heat and mass transfer coefficients will reach constant values. In this regime, Eqs. (13)-(16) would no longer be valid and therefore not recommended for pads of thickness greater than the range of $250-300 \mathrm{~mm}$.

The assumption that heat and mass transfers occurring in a given flow regime proceed at similar rates that produce an analogy between these processes:

$\frac{h_{\mathrm{H}}}{h_{\mathrm{M}}}=\rho_{\mathrm{a}} C_{\mathrm{Pa}} L e^{2 / 3}\left(\frac{L e_{\mathrm{s}}}{L e}\right)^{1 / 4}$,

where $L e$ is the Lewis number $(L e=\alpha / D)$, and $L e_{\mathrm{S}}$ is the Lewis number at water temperature. 

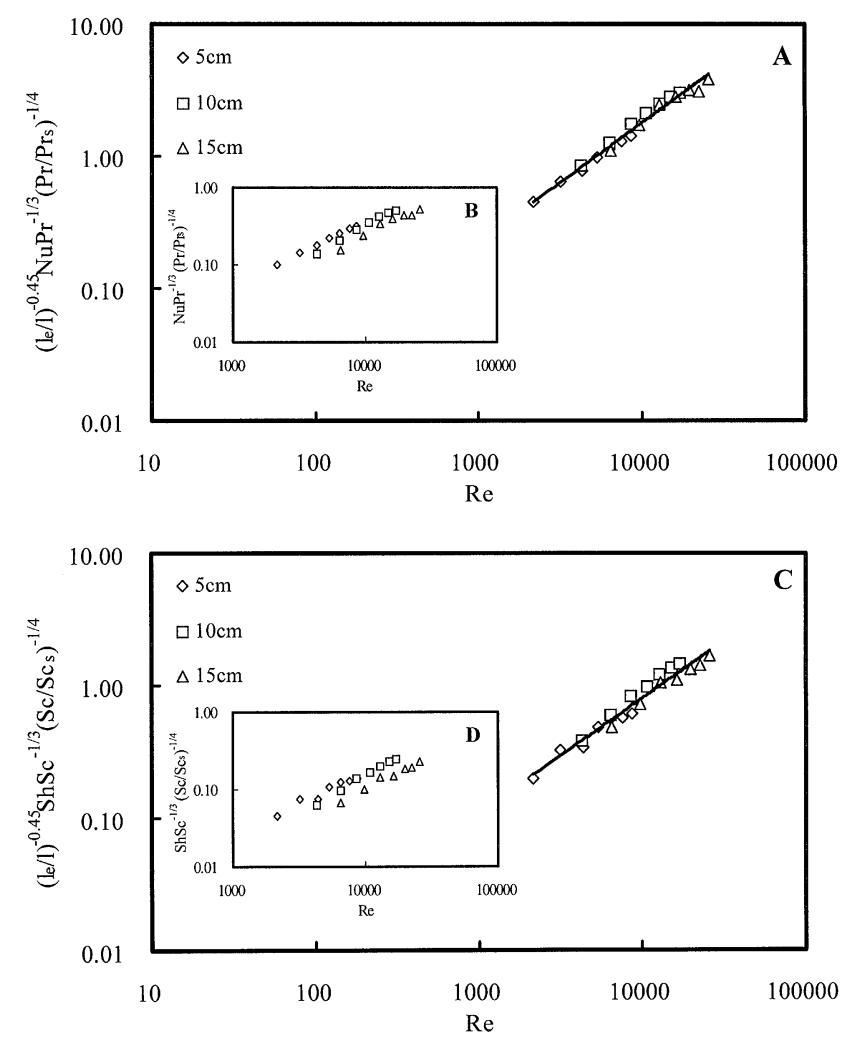

Fig. 8. Correlations of nondimensionalized transfer coefficients of heat: (A) calibrated, (B) uncalibrated; and mass: (C) calibrated, (D) uncalibrated for coarse fabric PVC sponge mesh.

Dividing Eq. (13) by Eq. (14) gives an analogous expression for coarse fabric PVC sponge:

$\frac{h_{\mathrm{H}}}{h_{\mathrm{M}}}=1.33 \rho_{\mathrm{a}} C_{\mathrm{Pa}} L e^{2 / 3}\left(\frac{L e_{\mathrm{s}}}{L e}\right)^{1 / 4}$.

Dividing Eq. (15) by Eq. (16) gives an analogous expression for fine fabric PVC sponge:

$\frac{h_{\mathrm{H}}}{h_{\mathrm{M}}}=2.76 \rho_{\mathrm{a}} C_{\mathrm{Pa}} L e^{2 / 3}\left(\frac{L e_{\mathrm{s}}}{L e}\right)^{1 / 4}$.

Because the analogy in Eq. (17) assumes that turbulent momentum and heat and mass diffusivities are equal [22], it is not unreasonable to expect small differences between the analogy and experimental results.

Equations and charts have been presented, which enable the calculation of the saturation efficiency of the system and required heat and mass transfer coefficients. It has been shown that estimates of effective values of the heat and mass transfer coefficients in a small-scale pad-fan system can be obtained through wind tunnel measurements. It should be emphasized that a wide range of operating conditions must be applied to the wind tunnel experiments, to allow the evaluation of average transfer coefficients by means of the regression equations. This may prove difficult in commercial buildings, unless they are monitored over entire cooling season.
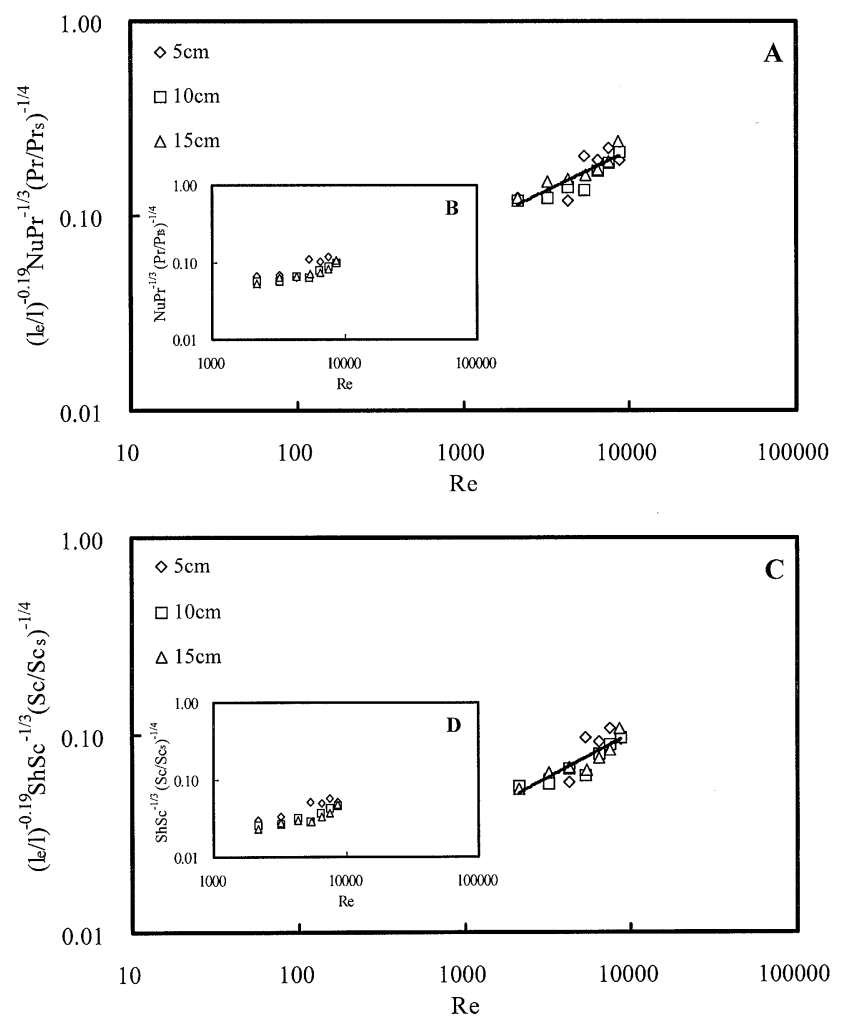

Fig. 9. Correlations of nondimensionalized transfer coefficients of heat: (A) calibrated, (B) uncalibrated; and mass: (C) calibrated, (D) uncalibrated for fine fabric PVC sponge mesh.

\section{Conclusions}

We have presented here an investigation into the underlying mechanical and thermodynamic phenomena of a pad-fan system in a wind tunnel. A compact wind tunnel was designed particularly for small-scale evaporative cooling-process experiment. The present study successfully demonstrated the feasibility of simulating a padfan system based on the measurements of air velocity, dry- and wet-bulb temperatures, and static pressure drop in transition. The accuracy and consistency of the measurements were found to be satisfactory. Correlation has been found on the basis of these results for heat and mass transfer coefficients in a evaporative cooling process for two alternative pad materials of coarse fabric PVC sponge mesh (pinhole size $=2.5 \mathrm{~mm}$ diameter) and fine fabric PVC sponge mesh (pinhole size $=7.5 \mathrm{~mm}$ diameter). It would seem that, on a theoretical basis, the use of these correlations in sizing evaporative equipment provides more design details than the traditional rule of thumb methods. The system is feasible and could have wide application in thermal environmental control in Taiwan region.

The procedure used in this study allows accurate determination of evaporative cooling performance in terms of evaporative cooling efficiency and static pressure drop. Cooling 
efficiencies for coarse fabric PVC sponge ranged from 63.88 to $64.77 \%, 80.50$ to $81.68 \%$, and 81.75 to $86.32 \%$, respectively, for 50, 100, and $150 \mathrm{~mm}$ thickness under normal operating air velocities of $1.0-1.5 \mathrm{~m} \mathrm{~s}^{-1}$. Cooling efficiencies for fine fabric PVC sponge ranged from 47.22 to $57.23 \%$, 62.93 to $72.25 \%$, and 76.68 to $85.51 \%$ for 50,100 , and $150 \mathrm{~mm}$ thickness, respectively, under normal operating air velocities.

Our demonstration of the complex interaction of the relevant system parameters in the current evaporative cooling problem correlates well with previous investigations in that certain investigators have recognized the possible importance of parameters in system performance. The wind tunnel results cannot represent the actual evaporative process with certainty, but instead must represent the expected cooling process with reasonable compliance. In the light of the possible conditions in field installations, the range in cooling efficiencies observed in the wind tunnel under these disparate conditions seems rather narrow. From a practical perspective, however, the narrow range is preferred. Whether the cooling efficiencies for other alternative pad media are confined to such relative ranges remains to be seen.

\section{References}

[1] Gates RS, Usry JL, Nienaber JA. An optimal misting method for cooling livestock housing. Transactions of ASAE 1991;34(5): 2199-206.

[2] Bottcher RW, Baughman GR, Gates RS. Characterizing efficiency of misting systems for poultry. Transactions of ASAE 1991;34(2): $586-90$.

[3] Ryan DP, Boland MP, Kopel E. Evaluating two different evaporative cooling management systems for dairy cows in a hot, dry climate. Journal of Dairy Science 1992;75(4):1052-9.

[4] Aljmal K. Greenhouse cooling in hot countries. Energy 1994;19(11):1187-92.

[5] Ali AKA, A1-Haidary AA, Alshaikh MA. The effect of evaporative cooling in alleviating seasonal differences in milk production of Almarai dairy farms in the Kingdom of Saudi Arabia. Asia Austral. Journal of Animal 1999;12(4):590-6.

[6] Arbel A, Yekutieli O, Barak M. Performance of a fog system for cooling greenhouses. Journal of Agricultural Engineering Research 1999;72(2):129-36.
[7] Kimball BA, Benham DS, Wiersma F. Heat and mass transfer coefficients for water and air in aspen excelsior pads. Transactions of ASAE 1977;20:509-14.

[8] Langhans RW. Greenhouse management, 3rd ed. Ithaca, New York: Halcyon Press of Ithaca, 1980.

[9] Murr JM, Zaleski RH. A study of evaporative cooling pad media. OK: Acme Engineering and Manufacturing Crop, 1982.

[10] Dowdy JA, Reid RL, Handy ET. Experimental determination of heat and mass transfer coefficients in aspen pads. ASHRAE Transactions 1986;92(2a):60-70.

[11] Dowdy JA, Karabash NS. Experimental determination of heat and mass transfer coefficients in rigid impregnated cellulose evaporative media. ASHRAE Transactions 1987;93(2):382-95.

[12] Koca RW, Hughes WC, Christianson LL. Evaporative cooling pads: test, procedure and evaluation. Applied Engineering in Agriculture 1991;7(4):485-90.

[13] Beaudin D. Evaporative cooling system for remote medical center. ASHRAE Journal 1996;38(5):35-8.

[14] Giabaklou Z, Ballinger JA. A passive evaporative cooling system by natural ventilation. Building and Environment 1996;31(6):503-7.

[15] Mathews EW, Kleingled M, Grobler LJ. Integrated simulation of buildings and evaporative cooling systems. Building and Environment 1994;29(2):197-206.

[16] Abdalla AM, Narendran R. Utilization of wind power and wetted pads to evaporatively cool dairy cow sheds under hot and arid climate conditions. Agricultural Mechanization in Asia, Africa, and Latin America 1990;21(4):33-7.

[17] Liao CM, Singh S, Wang TS. Characterizing the performance of alternative evaporative cooling pad media in thermal environmental control applications. Journal of Environmental Science Health A 1998;33(7):1391-417.

[18] Dzivama AU, Aboaba FO, Binder UB. Evaluation of materials in construction of active evaporative cooler for storage of fruits and vegetables in arid environments. Agricultural Mechanization in Asia, Africa, and Latin America 1999;30(3):51-5.

[19] Mannix JG. Evaluation of convective heat transfer coefficient of an evaporative cooling pad. Unpublished Master thesis. Aubum Univ, Aubum, AL, 1981.

[20] Bradshaw P, Pankhurst RC. The design of low-speed wind tunnel. Progress in Aerospace Science 1964;5(1):1-10.

[21] Rae Jr. WH, Pope A. Low-speed wind tunnel testing. New York: Wiley, 1984.

[22] Incropera FP, DeWitt DP. Fundamentals of heat and mass transfer, 4th ed. New York: Wiley, 1996.

[23] Kreith F, Bohn MS. Principles of heat transfer, 5th ed. New York: West Publishing Company, 1993.

[24] ASHRAE. ASHRAE handbook of fundamentals. Altanta, GA: American Society of Heating, Refrigerating and Air-Conditioning, Inc., 1993.

[25] Holman JP. Thermodynamics. New York: McGraw-Hill, 1980. 